\title{
Thermal limits for industrial workers
}

\author{
C. R. BELL' AND A. J. WATTS ${ }^{2}$ \\ Medical Research Council Environmental Physiology Unit, London School of Hygiene and \\ Tropical Medicine, London WC1
}

\begin{abstract}
Bell, C. R., and Watts, A. J. (1971). Brit. J. industr. Med., 28, 259-264. Thermal limits for industrial workers. The literature on relationships between man's comfort, efficiency, and physical well-being and the nature of his thermal working environment is diverse and highly specific. Industrial practice requires more general 'concensus' data on which to base reasonable recommendations for the establishment of thermal environmental limits. A series of three such limits is proposed which provide protection of the workers' comfort, efficiency, and physiological safety.

For sedentary workers it is suggested that in summer an upper limit of $21.8^{\circ} \mathrm{C}$ C.E.T. is advisable if not less than $80 \%$ of workers are to be free from discomfort. Against a similar criterion in winter a lower limit of $15.5^{\circ} \mathrm{C} \mathrm{C.E.T.} \mathrm{is} \mathrm{proposed.} \mathrm{An} \mathrm{extrapolation} \mathrm{of} \mathrm{data} \mathrm{from}$ laboratory to industrial work-places provides a suggested limit for efficiency at skilled tasks at $26.7^{\circ} \mathrm{C}$ C.E.T. Finally, a limit of environmental severity based upon an absence of severe physiological distress in $95 \%$ of exposed workers is proposed which varies with the age and physical fitness of the workers and the physical demands of the work they are called upon to perform.
\end{abstract}

It is necessary to search the engineering, ergonomic, physiological, and psychological literature of the past half-century to collate the considerable body of data on human reactions to the thermal environment. Several substantial reviews of particular aspects of these data have been written (Provins, 1958; Bell and Provins, 1962; Pepler, 1964; Wing, 1965; Bell, 1967; Poulton, 1970) but, because of the dependence of subjective comfort, performance efficiency, and physiological well-being upon the multiplicity of factors illustrated in these reviews, it is seldom easy to extract recommendations for industrial practice which would obtain in a wide variety of workplaces.

Rohles (1967) has analysed this complexity of variables into three categories. One group contains all those physical factors which impinge upon man and comprise his working environment. A second

\footnotetext{
${ }^{1}$ Present address: Department of Psychology, The University, Manchester, M13 9PL, England.

2Present address: Department of Psychology, Western Australian Institute of Technology, Hayman Road, Bentley 6102, Western Australia.
}

group contains all those reciprocative factors which comprise man's responses to his physical environment. The third group of variables are those organismic factors which comprise those characteristics of the man himself which influence the ways in which he responds to environmental stresses.

Classificatory systems, like that proposed by Rohles and that presented here, may be seen as attempts to introduce order into confusingly complex data. Such order, whilst failing to do justice to the rich variety of data it seeks to encompass, is essential in the framing of recommendations which can be seen to have use for industrial advisers. The limits of thermal severity proposed here permit a choice to be made of the kind of criterion of thermal hazard which is considered to be appropriate to any particular industrial environment in which a thermal problem may occur.

One thermal limit is defined in terms of a criterion of the protection of a given proportion of sedentary workers from feelings of discomfort. A second thermal limit relates to the adoption of a criterion which seeks to prevent significant deterioration in 
the performance of skilled and semi-skilled tasks. The third thermal limit proposed is based upon a criterion of physiological safety of exposed workers.
Environmental limits based upon considerations of each of these three criteria are presented in the chart (Figure). Amplifications of the nature of these
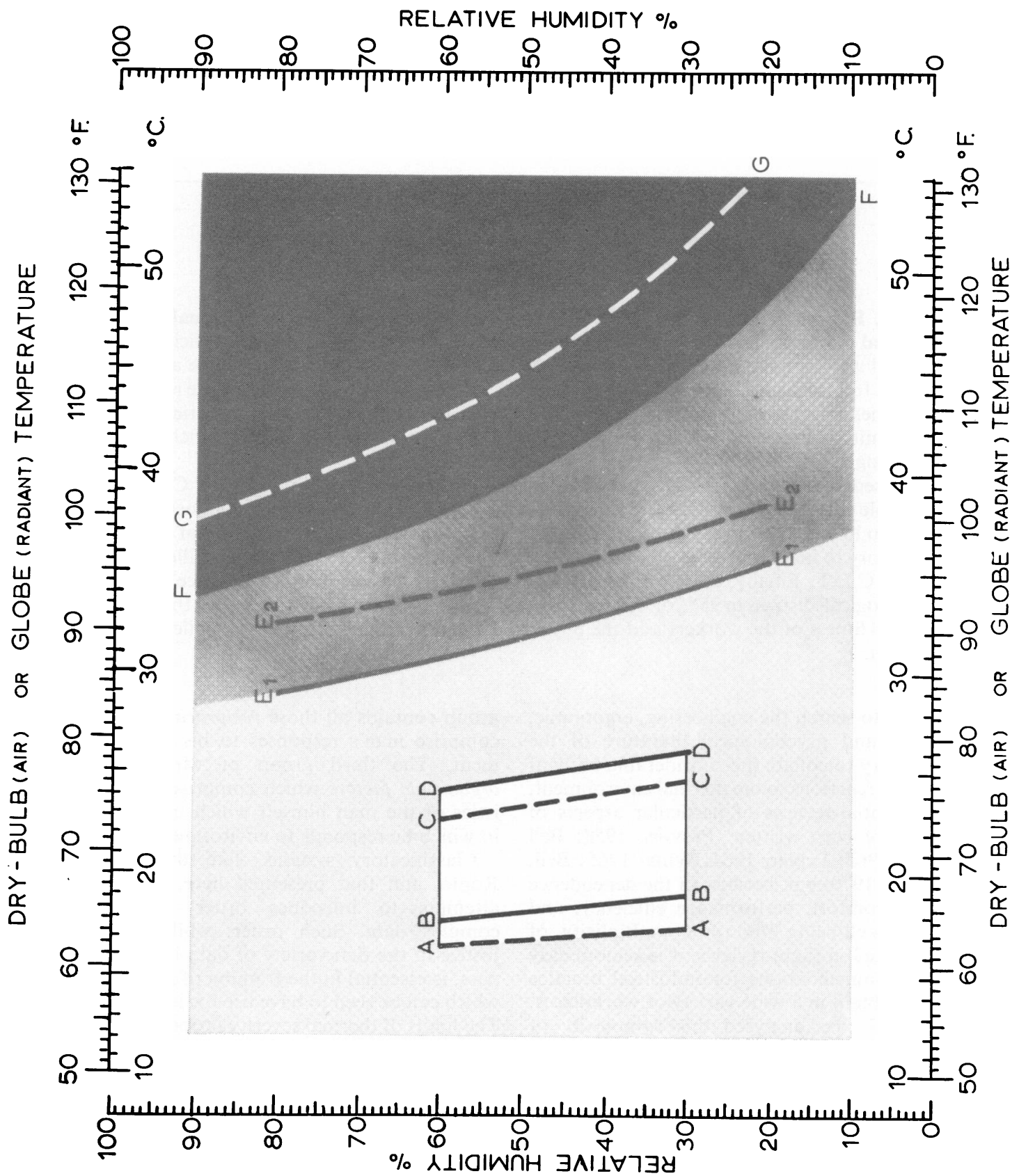

FIGURE Chart showing limits of environmental severity for workers' winter comfort $(A-A$ to $C-C)$, summer comfort $(B-B$ to $D-D)$, working efficiency $\left(E_{1}-E_{1}\right.$ and $\left.E_{2}-E_{2}\right)$, and physiological safety $(F-F$ and $G-G)$. For fuller explanation see text. 
limits are provided in each of the three sections below. In sections I and II the initials C.E.T. refer to values on the Normal Scale of Corrected Effective Temperature (Smith, 1955). This scale combines into a single value all those combinations of air and radiant temperatures, humidity levels, and air speeds which produce a similar sensation of warmth in lightly clothed individuals as an environment with an air or radiant temperature of that value and $100 \%$ saturation of the air with water vapour and minimal air movement (Houghten and Yagloglou, 1923a, 1923b, 1924; Yaglou, 1926; Bedford, 1946; Newburgh, 1949).

\section{Section I: Comfort}

The lines $\mathbf{A}-\mathbf{A}$ and $\mathbf{C}-\mathrm{C}$ on the chart describe the winter range of thermal conditions within which it is expected that not less than $80 \%$ of seated workers performing light manual tasks will be thermally comfortable. The relative humidity limits of $30 \%$ and $60 \%$ are recommended irrespective of air or radiant temperature or air speed. Within a recommended range of air speeds of 0.05 to $0.15 \mathrm{~m} / \mathrm{s}$, the lines $\mathbf{A}-\mathbf{A}$ and $\mathbf{C}-\mathbf{C}$ represent environments of $15.5^{\circ} \mathrm{C}$ C.E.T. and $20.7^{\circ} \mathrm{C}$ C.E.T. respectively. The recommended optimum winter comfort environment within this range is $17 \cdot 8^{\circ} \mathrm{C} \mathrm{C.E.T.}$

The lines B-B and D-D on the chart describe the summer range of thermal conditions within which it is expected that not less than $80 \%$ of seated workers performing light manual tasks will be thermally comfortable. Within recommended ranges of relative humidity of 30 to $60 \%$ and air speed of 0.05 to $0.15 \mathrm{~m} / \mathrm{s}$ these lines represent environments of $16.7^{\circ} \mathrm{C} \mathrm{C.E.T}$. and $21.8^{\circ} \mathrm{C}$ C.E.T. respectively. The recommended optimum summer comfort environment is $18 \cdot 3^{\circ} \mathrm{C}$ C.E.T.

These recommendations were derived from two thermal comfort surveys in industry (Bedford, 1936; Hickish, 1955). Corrections have been made to the original survey data to allow for the sex composition of the original groups and to take account of an apparent upward drift in comfort levels over time. These corrections were based upon a study of sex differences in comfort judgements by Yaglou and Messer (1941) and upon observations on changes in comfort levels made by the Institute of Heating and Ventilation Engineers (I.H.V.E. Guide, 1965). Upward corrections of $2 \cdot 2^{\circ} \mathrm{C}$ on Bedford's winter air temperature data and of $1.0^{\circ} \mathrm{C}$ on Hickish's summer air temperature data were made.

No original data were available for the determination of the lower summer limit denoted by the line B - B on the chart. This was derived by extrapolation from the magnitude of the winter comfort range and the location of the upper limit of the summer comfort range. This was possible only by assuming that the effect of acclimatization to summer conditions will be equally influential in altering both the upper and lower limits of comfort from winter to summer.

Attempts to put these recommended limits into practice in particular industrial environments should take account of several important factors.

\section{Work level}

Sedentary light manual work has been taken as a base-line for the recommended limits shown on the chart. However, increases in metabolic heat production occur with increases in the energy expenditure requirements of other levels of physical work. In these situations more heat must be dissipated from the body if comfort is to be achieved or maintained. Cooler environments than those shown on the chart are more suitable for higher work rates. Where the work rate is sufficient to initiate general body sweating then satisfactory rates of heat loss may be achieved by increasing the level of air movement above the recommended speed of 0.15 $\mathrm{m} / \mathrm{s}$ to facilitate the evaporation of sweat.

\section{Clothing and sex differences}

An upward drift in comfortable levels of warmth may be largely a reflection of a tendency for less or lighter clothing to be worn now than was the case some 40 years ago. Differences in the insulative properties of clothing worn typically by men or women may wholly account for the apparent preference among women for environmental temperatures higher than those preferred by men (Yaglou and Messer, 1941). The recommended levels of temperature shown in the chart may need to be lowered or raised by up to $1.4^{\circ} \mathrm{C} \mathrm{C.E.T}$. when applied to predominantly male or female working groups respectively.

\section{Comfort standard}

The criterion of $80 \%$ comfortable used in the chart is generally considered to be the highest attainable in any given environment because of the wide range of individual differences in temperature preferences. If a criterion of $60 \%$ comfortable is chosen, then the range of acceptable temperature conditions may be extended by $2 \cdot 0^{\circ} \mathrm{C} \mathrm{C.E.T.} \mathrm{at} \mathrm{both} \mathrm{the} \mathrm{upper} \mathrm{and}$ lower ends of the range.

\section{Section II: Working efficiency}

An upper limit of thermal stress permissible without a loss of working efficiency has been taken as $26 \cdot 7^{\circ} \mathrm{C}$ C.E.T. This limit is indicated on the chart by the lines $E_{1}-E_{1}$ and $E_{2}-E_{2}$. The line $E_{1}-E_{1}$ on the chart represents an environment of $26.7^{\circ} \mathrm{C}$ C.E.T. when air movement is only $0.5 \mathrm{~m} / \mathrm{s}$. Because the same C.E.T. value can be obtained with higher air 
or radiant temperatures and humidities provided there has been an increase in air movement, the line $E_{2}-E_{2}$ on the chart also represents an environment of $26.7^{\circ} \mathrm{C} \mathrm{C.E.T.} \mathrm{but} \mathrm{with} \mathrm{an} \mathrm{air} \mathrm{movement} \mathrm{of}$ $5.1 \mathrm{~m} / \mathrm{s}$. Thus the area between these two lines contains equivalent conditions of environmental thermal severity dependent upon a range of air movements from 0.5 to $5 \cdot 1 \mathrm{~m} / \mathrm{s}$.

When skilled or semi-skilled workers are exposed to thermal environments to which they are unaccustomed their normal level of efficiency at their jobs may be reduced. This deterioration may show itself in more frequent performance of wrong actions or more frequent failures to perform appropriate actions. The limits for efficient working described here are those environmental conditions below which such deteriorations are unlikely to occur. The tasks concerned are those that do not require hard physical work.

In environments warmer than $26.7^{\circ} \mathrm{C}$ C.E.T. the probability of inefficiency in skilled work becomes greater as conditions become thermally more severe. In some jobs which demand skilled manipulation of unanchored objects any increases in air movement introduced in order to maintain a low C.E.T. value may themselves become a cause of inefficiency. For many tasks those workers who find their jobs most difficult may demonstrate inefficiency at levels of thermal stress lower than those which evoke deterioration in more competent workers. Similarly, workers who have had no previous experience of work in warm environments may be more susceptible to loss of efficiency than those workers who are familiar with such environments.

The limit of working efficiency of $26.7^{\circ} \mathrm{C} \mathrm{C.E.T.}$ has been extracted from reports of laboratory studies. In these contexts it has been rare for the effects of exposure to uncomfortable thermal environments to be examined over a length of time comparable to the duration of an industrial work shift. Tasks have been performed for continuous periods of time of usually less than one hour's duration. The personnel examined in these laboratory studies have tended to be students, military subjects or laboratory staff who may not have been representative, in their responses, of the responses of industrial workers engaged in their everyday activities.

Very few studies have investigated the effect of exposure to uncomfortably warm conditions in real-life industrial situations. Several surveys of industrial plant were published between the wars. These reports originated in the work of the Industrial Fatigue (Health) Research Board of the Medical Research Council and the Department of Scientific and Industrial Research. The general conclusions which may be derived from these studies are that overall output per man-hour tends to fall and the frequency of minor accidents tends to increase when workshop temperatures rise above seasonal norms and when the increase in temperature has not been counteracted by improvements in ventilation.

Some of the types of tasks on which a deterioration in performance has been demonstrated in laboratory environments more severe thermally than $26.7^{\circ} \mathrm{C}$ C.E.T. are:

(1) mental tasks requiring complex decision making (Pepler, 1958), arithmetic and number checking (Viteles and Smith, 1946), recording of morse messages (Mackworth, 1946), and fault tracing in electrical circuits (Carpenter, 1946);

(2) handling tasks requiring fine motor co-ordination (Weiner and Hutchinson, 1945) and continuous target tracking (Viteles and Smith, 1946; Carpenter, 1950; Mackworth, 1950; Teichner and Wehrkamp, 1954; Russell, 1957); and

(3) tasks requiring a high level of maintained attention (Mackworth, 1950; Bursill, 1958; Bell, Provins, and Hiorns, 1964; Bell and Provins, 1965).

From these studies it appears that tasks which present most difficulty - in terms of the pacing of the work, the complexity of the task demands, and the level of the performer's skill - are more susceptible to deterioration in high temperature conditions than are those tasks which the worker finds present less stress for him.

\section{Section III: Physiological safety}

The lines $A-A$ to $E_{2}-E_{2}$ on the chart represent values of environmental severity expressed as Corrected Effective Temperatures. The lines F-F and $G-G$ described in this section refer to levels of thermal severity greater than those which can be adequately expressed in terms of C.E.T. values.

The limit represented by the line $F-F$ on the chart indicates that level of thermal severity at which only a small proportion of workers (about $5 \%$ ) will be likely to suffer any adverse physiological effects during an exposure to the thermal environment. This limit is based upon the responses of fit, young men performing physical work at energy expenditure levels of about 291 to $349 \mathrm{~J} / \mathrm{s}$ (250 to $300 \mathrm{kcal} / \mathrm{hr}$ ) over a period of two to four hours. More than $5 \%$ of the workers who are older and less physically fit may begin to experience nausea, dizziness, headaches or fainting spells at the level of severity indicated by the line F-F on the chart. With longer exposure, or with more physically demanding work rates, the limit of physiological safety may have to be placed nearer to the limits represented by the $E_{1}-E_{1}$ and $E_{2}-E_{2}$ lines. Indeed, for an eight-hour shift of continuous work at an average of 442 to $465 \mathrm{~J} / \mathrm{s} \mathrm{(380} \mathrm{to}$ $400 \mathrm{kcal} / \mathrm{hr}$ ) the line $\mathrm{E}_{1}-\mathrm{E}_{1}$ may be taken as the limit of physiological safety. Conversely, with shorter exposures and less physically demanding 
work rates the limit of physiological safety may be placed closer to the line $G-G$ on the chart which represents the safety limit of fit, young men working at about $116 \mathrm{~J} / \mathrm{s}(100 \mathrm{kcal} / \mathrm{hr})$ over a period of two to four hours.

Studies of physiological safety in terms of maintained levels of rectal temperature over a period of about eight hours at average work rates of $442 \mathrm{~J} / \mathrm{s}$ $(380 \mathrm{kcal} / \mathrm{hr}), 325 \mathrm{~J} / \mathrm{s}(280 \mathrm{kcal} / \mathrm{hr})$, and $198 \mathrm{~J} / \mathrm{s}$ $(170 \mathrm{kcal} / \mathrm{hr})$ have suggested limits which lie between those indicated by the lines $E_{1}-E_{1}$ and $F-F$ on the chart (Lind, 1963). Other studies of continuous work over periods of four hours at average rates of $209 \mathrm{~J} / \mathrm{s}$ $(180 \mathrm{kcal} / \mathrm{hr})$ and $232 \mathrm{~J} / \mathrm{s}(200 \mathrm{kcal} / \mathrm{hr})$ have suggested limits which lie between those indicated by the lines $F-F$ and $G-G$ on the chart (Robinson, Turrell, and Gerking, 1945; Ellis, Ferres, Lind, and Newling, 1953). The lines $F-F$ and $G-G$ were derived from studies of the incidence of heat collapse in fit young men reported by Provins, Hellon, Bell, and Hiorns (1962), Bell et al. (1965), and Bell and Walters (1969).

A general statement can be drawn from all these and other similar studies to the effect that a limit of thermal severity against the criterion of physiological safety is closer to the line $E_{1}-E_{1}$ when physiological safety is defined as maintenance body temperature, and when $(a)$ the physical work load of the job is greater, $(b)$ the duration of continuous work is longer, and $(c)$ the workers are less fit, less young, and less acclimatized to work in heat. A limit of thermal severity against the criterion of physiological safety is closer to the line $G-G$ when physiological safety is defined in terms of proportions of exposed persons who suffer from heat collapse, and when $(a)$ the physical demands of the job are less, $(b)$ the duration of work is less than two or four hours, and (c) the workers are young, fit, and acclimatized to work in the heat.

\section{Discussion}

Although the object of this report has been to provide practicable recommendations for the protection of industrial workers from thermal environmental hazards, there are, of course, many aspects of the industrial worker's environment which may be equally important to his comfort, working efficiency, and physiological safety which have not been included in the limits proposed here.

Two major considerations need to be noted. Firstly, it is extremely rare for any real-life environment to be characterized by thermal hazard alone. The noise, lighting, and air pollution aspects of the physical environment will often need to be considered in conjunction with the thermal characteristics of the environment. The relative weight to be given to each of these parameters may be highly specific to a particular industrial situation being examined. At present there is not much firm evidence on the ways in which combinations of stresses from physical environmental variables affect workers (Poulton, 1970).

A second consideration, when assessing the necessity of implementing the recommended thermal limits suggested here, relates to the nature of any effects on the industrial worker which are chosen as 'success criteria'. Much of the literature on the ergonomics of the physical environment gives the impression that the goals of research have been the elimination of potential or present hazards. Little attention appears to have been paid to the promotion of positive benefits for the industrial worker. This may be because, as Howells (1969) has suggested, improvements in 'job hygiene' factors, whilst reducing sources of job dissatisfaction, contribute little to a positive promotion of job satisfaction. Thus the criteria frequently chosen in the studies used as bases for the proposed environmental limits have been concerned with the elimination of discomfort, inefficiency, and hazardous thermal strain.

Both these considerations serve to emphasize the complex nature of the interactions of industrial workers with their working environments. Realistically, it might be argued that the piecemeal implementation of recommendations concerned with particular aspects of industrial environments may pave the way for later research to concentrate on more complex questions. It has been from this point of view that the thermal limits described in this report have been presented.

This report was compiled when both authors were members of the Medical Research Council's Environmental Physiology Unit. Grateful thanks are due to the Director of that Unit, Professor J. S. Weiner, for his advice and encouragement, and to two members of his staff, Mr. D. E. Lee and Mr. S. Prestidge, for their aid in the preparation and reproduction of the chart.

\section{References}

Bedford, T. (1936). The Warmth Factor in Comfort at Work. Medical Research Council and Department of Scientific and Industrial Research, Industrial Health Research Board Report, no. 76.

(1946). Environmental Warmth and its Measurement. Medical Research Council War Memorandum no. 17, H.M.S.O., London.

Bell, C. R. (1967). Hot environments and performance. In The Effects of Abnormal Physical Conditions at Work, edited by C. N. Davies, P. R. Davis, and F. H. Tyrer, pp. 60-73. Livingstone, Edinburgh.

, Hellon, R. F., Hiorns, R. W., Nicol, P. B., and Provins, K. A. (1965). Safe exposure of men to severe heat. J. appl. Physiol., 20, 288-292.

, and Provins, K. A. (1962). Effects of high temperature environmental conditions on human performance. $J$. occup. Med., 4, 202-211.

, and - (1965). Peripheral attention of two age groups in hot conditions. J. Geront., 20, 72-75. 
,, , and Hiorns, R. W. (1964). Visual and auditory vigilance during exposure to hot and humid conditions. Ergonomics, 7, 279-288.

—, and Walters, J. D. (1969). Reactions of men working in hot and humid conditions. J. appl. Physiol., 27, 684-686.

Bursill, A. E. (1958). The restriction of peripheral vision during exposure to hot and humid conditions. Quart. $J$. exp. Psychol., 10, 113-129.

Carpenter, A. (1946). The Effect of Room Temperature on the Performance of the Resistance Box Test. Medical Research Council Applied Psychology Unit (Cambridge), Report no. A.P.U. 50.

- (1950). A comparison of the influence of handle load and of unfavourable atmospheric conditions on a tracking task. Quart. J. exp. Psychol., 2, 1-6.

Ellis, F. P., Ferres, H. M., Lind, A. R., and Newling, P. B. (1953). The Upper Tolerable Levels of Warmth for Acclimatized European Men Working in the Tropics. Medical Research Council Royal Naval Personnel Research Committee, Report no. RNP 53/759.

Hickish, D. E. (1955). Thermal sensations of workers in light industry in summer: a field study in Southern England, J. Hyg. (Lond.), 53, 112-123.

Houghten, F. C., and Yagloglou, C. P. (1923a). Determining equal comfort lines. J. Amer. Soc. heat. vent. Engrs, 29, 165-176.

- and - (1923b). Determination of the comfort zone. J. Amer. Soc. heat. vent. Engrs, 29, 515-536.

duced by various air velocities. J. Amer. Soc. heat. vent. Engrs, 30, 169-184.

Howells, G. W. (1969). Human Aspects of Management, Heinemann, London.

Institute of Heating and Ventilation Engineers Guide (1965). Section 4-Comfort.

Lind, A. R. (1963). Tolerable limits for prolonged and intermittent exposures to heat. In Temperature: its Measurement and Control in Science and Industry, Part 3, edited by J. D. Hardy. Reinhold, New York.

Mackworth, N. H. (1946). Effects of heat on wireless telegraphy operators hearing and recording morse messages. Brit. J. industr. Med., 3, 143-158.

(1950). Researches on the Measurement of Human
Performance. Spec. Rep. Ser. Med. Res. Coun. (Lond..) no. 268. H.M.S.O., London.

Newburgh, L. H. (1949). Physiology of Heat Regulation and the Science of Clothing. Saunders, Philadelphia.

Pepler, R. D. (1958). Warmth and performance: an investigation in the tropics. Ergonomics, 2, 63-88.

- (1964). Psychological effects of heat. In Heat Stress and Heat Disorders, by C. S. Leithead and A. R. Lind. Cassell, London.

Poulton, E. C. (1970). Environment and Human Efficiency. American Lecture Series. Thomas, Springfield, Illinois.

Provins, K. A. (1958). Environmental conditions and driving efficiency: a review. Ergonomics, 2, 97-107.

-, Hellon, R. F., Bell, C. R., and Hiorns, R. W. (1962). Tolerance to heat of subjects engaged in sedentary work. Ergonomics, 5, 93-97.

Robinson, S., Turrell, E. S., and Gerking, S. D. (1945). Physiologically equivalent conditions of air temperature and humidity. Amer. J. Physiol., 143, 21-32.

Rohles, F. H. (1967). Environmental psychology. Psychol. Today, June, pp. 54-63.

Russell, R. W. (1957). Effects of variations in ambient temperature on certain measures of tracking skill and sensory sensitivity. U.S. Army Medical Research Laboratory Report, no. 300/57.

Smith, F. E. (1955). Indices of Heat Stress. Medical Research Council Memorandum, no. 29. H.M.S.O., London.

Teichner, W. H., and Wehrkamp, R. F. (1954). Visual-motor performance as a function of short-duration ambient temperature. J. exp. Psychol., 47, 447-450.

Viteles, M. S., and Smith, K. R. (1946). An experimental investigation of the effect of change in atmospheric conditions and noise upon performance. Heat. Pip. Air Condit., 18, no. 3 (March), 107-112.

Weiner, J. S., and Hutchinson, J. C. D. (1945). Hot humid environment: its effects on the performance of a motor co-ordination test. Brit. J. industr. Med., 2, 154-157.

Wing, J. F. (1965). A Review of the Effects of High Ambient Temperature on Mental Performance. Wright-Patterson Air Force Base, Ohio, Technical Report, no. AMRLTDR-65-102.

Yaglou, C. P. (1926). The thermal index of atmospheric conditions and its application to sedentary and to industrial life. J. industr. Hyg., 8, 5-19.

air conditioning. J. Amer. med. Ass., 117, 1261-1262.

Received for publication December 10, 1970. 